\title{
Local Presentation of Substrate Molecules Directs Axon Specification by Cultured Hippocampal Neurons
}

\author{
Teresa Esch, ${ }^{1}$ Vance Lemmon, ${ }^{2}$ and Gary Banker ${ }^{3}$ \\ ${ }^{1}$ Department of Neuroscience, University of Virginia School of Medicine, Charlottesville, Virginia 22908, 2Department \\ of Neurosciences, Case Western Reserve University School of Medicine, Cleveland, Ohio 44106-4975, and ${ }^{3}$ Center \\ for Research on Occupational and Environmental Toxicology, Oregon Health Sciences University, Portland, Oregon
} 97201-3098

\begin{abstract}
Axon specification is a crucial, early step in neuronal development, but little is known about how this event is controlled in vivo. To test the hypothesis that local presentation of growthpromoting molecules can direct axon specification, we cultured hippocampal neurons on substrates patterned with stripes of poly-L-lysine and either laminin (LN) or the neuron-glia cell adhesion molecule (NgCAM). Although undifferentiated neurites contacted both substrates equally, axons formed preferentially on LN or NgCAM. Time-lapse studies revealed that changes in the growth pattern of a cell indicative of axon specification began almost immediately after the growth cone of one of the
\end{abstract}

neurites of the cell contacted LN or NgCAM. When cells were plated on alternating stripes of $\mathrm{LN}$ and $\mathrm{NgCAM}$, cells with their somata on LN usually formed axons on NgCAM, whereas those with somata on $\mathrm{NgCAM}$ preferentially formed axons on LN. This suggests that the change from one axon-promoting substrate to another also provides a signal sufficient to specify the axon. These results demonstrate that contact with preferred substrate molecules can govern which neurite becomes the axon and thus direct the development of neuronal polarity.

Key words: neuronal development; polarity; NgCAM; laminin; axonal specification; hippocampal cultures
Neurons must develop highly complex forms with morphologically and molecularly distinct axons and dendrites. The development of this polarity, which is crucial for nearly every aspect of neuronal function, generally begins with the formation of the axon. Although many studies have examined the cellular mechanisms that mediate axonal extension and guidance (for review, see Tanaka and Sabry, 1995; Tessier-Lavigne and Goodman, 1996; Suter and Forscher, 1998), most of these studies focus on later stages of axon growth, after the axon is clearly established. Considerably less is known about the very earliest steps in axon formation, when the axon is first specified.

The initial stages of axon development have been studied in greatest detail in cell cultures of hippocampal neurons from embryonic rats. When neurites first form, they cannot be distinguished as either axons or dendrites (Dotti et al., 1988). These so-called "minor processes" exhibit alternating periods of growth and retraction for 12-24 hr until one enters a prolonged growth period and begins to acquire axonal characteristics (Goslin and Banker, 1990); the remaining processes eventually become dendrites. Until the nascent axon reaches a length at least $10-15 \mu \mathrm{m}$ longer than any other process, it is morphologically and molecularly indistinguishable from the other minor processes. Furthermore, if the newly formed axon is transected near the soma, a new

\footnotetext{
Received Jan. 21, 1999; revised May 10, 1999; accepted May 21, 1999.

This research was supported by National Institutes of Health Grants NS17112 (G.B.) and EY5285 (V.L.). Teresa Esch was supported in part by a predoctoral fellowship from the National Science Foundation. We thank Hannelore Asmussen for preparation of the neuronal cultures and Ginger Withers, Chris Wallace, and Michelle Burack for helpful comments on this manuscript.

Correspondence should be addressed to Dr. Gary Banker, Center for Research on Occupational and Environmental Toxicology, Oregon Health Sciences University, 3181 SW Sam Jackson Park Road, L606, Portland, OR 97201-3098.

Dr. Esch's present address: Biology Department, University of California San Diego, La Jolla, CA 92093-0357.

Copyright (C) 1999 Society for Neuroscience $\quad 0270-6474 / 99 / 196417-10 \$ 05.00 / 0$
}

axon often emerges from a different minor process (Dotti and Banker, 1987; Goslin and Banker, 1989). Together, these results led to the hypothesis that, in culture, all of the initial processes formed by a neuron are capable of becoming axons. A direct test of this hypothesis requires a means to transform an as yetunspecified minor process into the axon of a cell.

In a model proposed by Goslin and Banker (1989) to explain the effects of transecting the axon at different distances from the cell body, specification of the axon is hypothesized to depend on its length relative to the other processes of the cell. Once one minor process grows significantly longer than the rest, it will become the axon. Many extracellular matrix and cell adhesion molecules enhance neurite growth and accelerate axon formation in hippocampal cultures (Lein et al., 1992; Lochter and Schachner, 1993; our unpublished observations). We reasoned that if such growth-promoting proteins could be presented selectively to a subset of the minor processes of a cell, this could enhance their chance of elongating and thus becoming the axon. To test this, we grew hippocampal neurons on coverslips coated with alternating stripes of poly-L-lysine (PLL) and either laminin (LN) or neuron-glia cell adhesion molecule (NgCAM), an L1like member of the immunoglobulin superfamily of cell adhesion molecules. Both LN and NgCAM previously have been shown to accelerate axon formation relative to PLL when presented as uniform substrates (Lein et al., 1992; our unpublished observations). In the present experiments, when cells attached near a boundary between substrates, some of their minor processes contacted one of the substrates and some contacted the other. Under these conditions we found that axons formed preferentially from neurites that contacted LN or NgCAM. When the growth cone of an as yet-unspecified process crossed from PLL onto LN or $\mathrm{NgCAM}$, its growth rapidly increased and the growth of the 

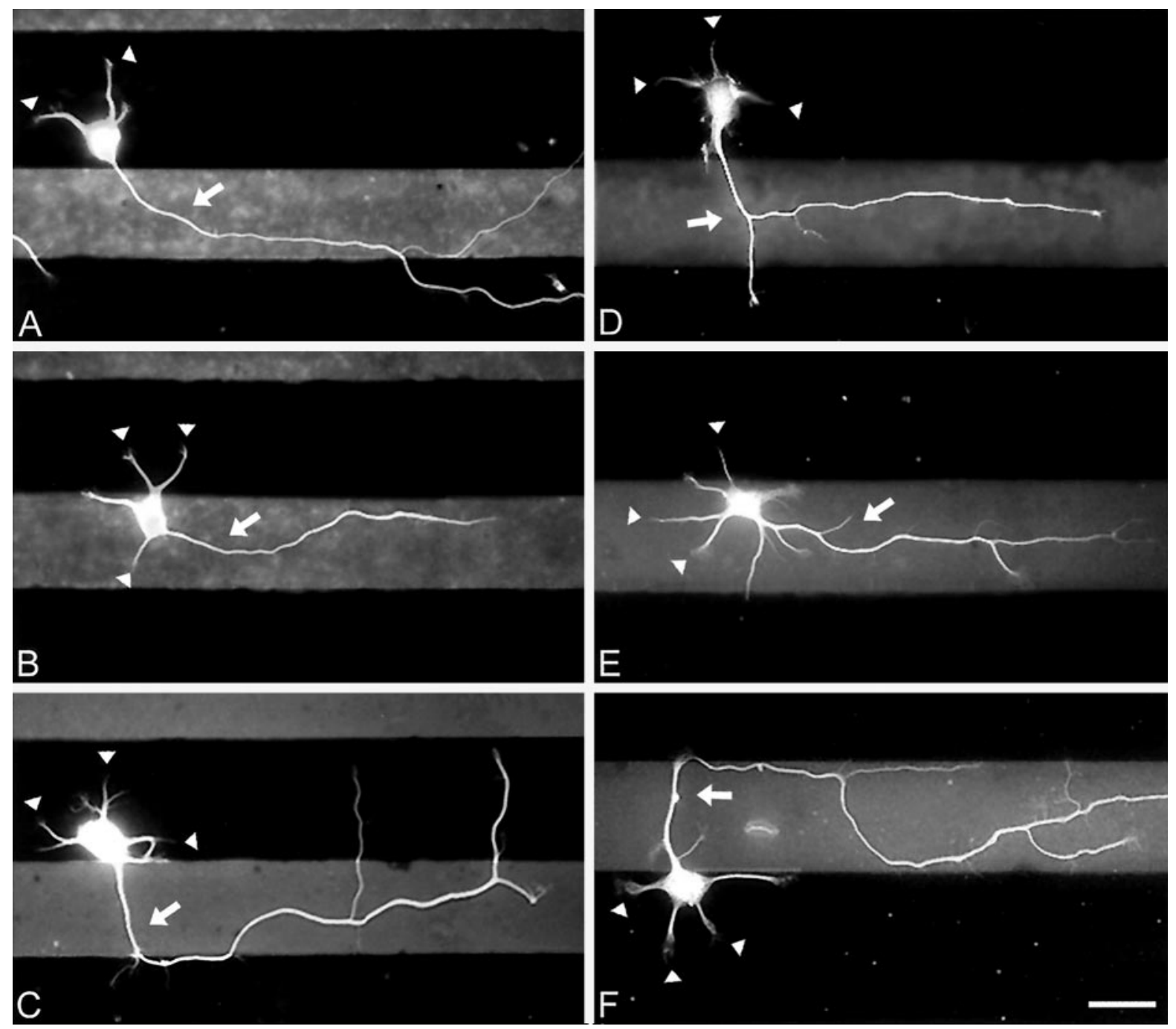

Figure 1. When hippocampal neurons are grown on striped substrates, axons form predominantly on one substrate. Neurons were cultured on substrates patterned with alternating stripes of PLL and LN $(A-C)$ or PLL and NgCAM $(D-F)$. When they were examined after 24 hr in culture, minor process growth cones (arrowheads) were positioned on both substrates, but axons (arrows) almost always formed on LN or NgCAM. Neurons were immunolabeled for tubulin, and the patterns were revealed by immunostaining for either LN or NgCAM so that PLL appears dark and LN or NgCAM appears light. Fluorescent images of neurons and stripes were superimposed. Scale bar, $25 \mu \mathrm{m}$.

remaining processes concurrently declined, leading to specification of the polarity of the cell. These results represent the first direct demonstration that any of the neurites that initially develop in culture are capable of becoming axons and that extracellular signals can govern the development of neuronal polarity by specifying which of these processes becomes the axon of the cell.

\section{MATERIALS AND METHODS}

\section{Substrate proteins and antibodies}

Mouse LN (from Engelbreth-Holm-Swarm sarcoma) was obtained from Life Technologies (Gaithersburg, MD). Poly-L-lysine (molecular weight, 30,000-70,000), protamine sulfate, and rabbit anti-tubulin were obtained from Sigma (St. Louis, MO). Fluorescein-conjugated bovine serum albumin (BSA) was obtained from Molecular Probes (Eugene, OR). Rabbit anti-LN was obtained from Telios Pharmaceuticals (San Diego, CA). NgCAM was purified from chick brains, using an affinity column conjugated with 8D9 antibodies (Lemmon and McLoon, 1986). TuJ1 (monoclonal anti-tubulin) and tau-1 antibodies were generously provided by Tony Frankfurter (University of Virginia, Charlottesville, VA).

\section{Substrate preparation}

Silicon matrix. Coverslips were patterned with alternating stripes of two substrates, using a silicon matrix obtained from Juergen Jung (MaxPlanck Institut, Tubingen, Germany), as described by Vielmetter et al. (1990). In brief, the matrices had parallel channels 45 or $60 \mu \mathrm{m}$ wide separated by spacers that were 35 or $40 \mu \mathrm{m}$ wide, respectively. When a glass coverslip is placed on this matrix, a protein solution can be injected into the channels so that it binds to the coverslip only along these lanes. If the lanes then are blocked with BSA, a second protein can be applied to the remainder of the coverslip.

\section{Procedure}

PLL/LN stripes. Acid-washed glass coverslips were incubated overnight in $1 \mathrm{mg} / \mathrm{ml}$ PLL in borate buffer at room temperature. Coverslips were rinsed several times with water, air-dried, and inverted onto the silicon matrix. Fluorescein-conjugated BSA ( $2 \%$ in PBS) was injected into the channels and incubated for $2 \mathrm{hr}$ at $37^{\circ} \mathrm{C}$ to block possible $\mathrm{LN}$ binding sites. The channels were rinsed three to four times by injecting PBS, after which the coverslips were removed and rinsed two times in water. LN (25 $\mu \mathrm{g} / \mathrm{ml}$ in PBS) was applied to the entire coverslip and incubated for $2 \mathrm{hr}$ at $37^{\circ} \mathrm{C}$. Under these conditions the laminin bound in stripes between the BSA-treated lanes. Coverslips were rinsed three times in water and 

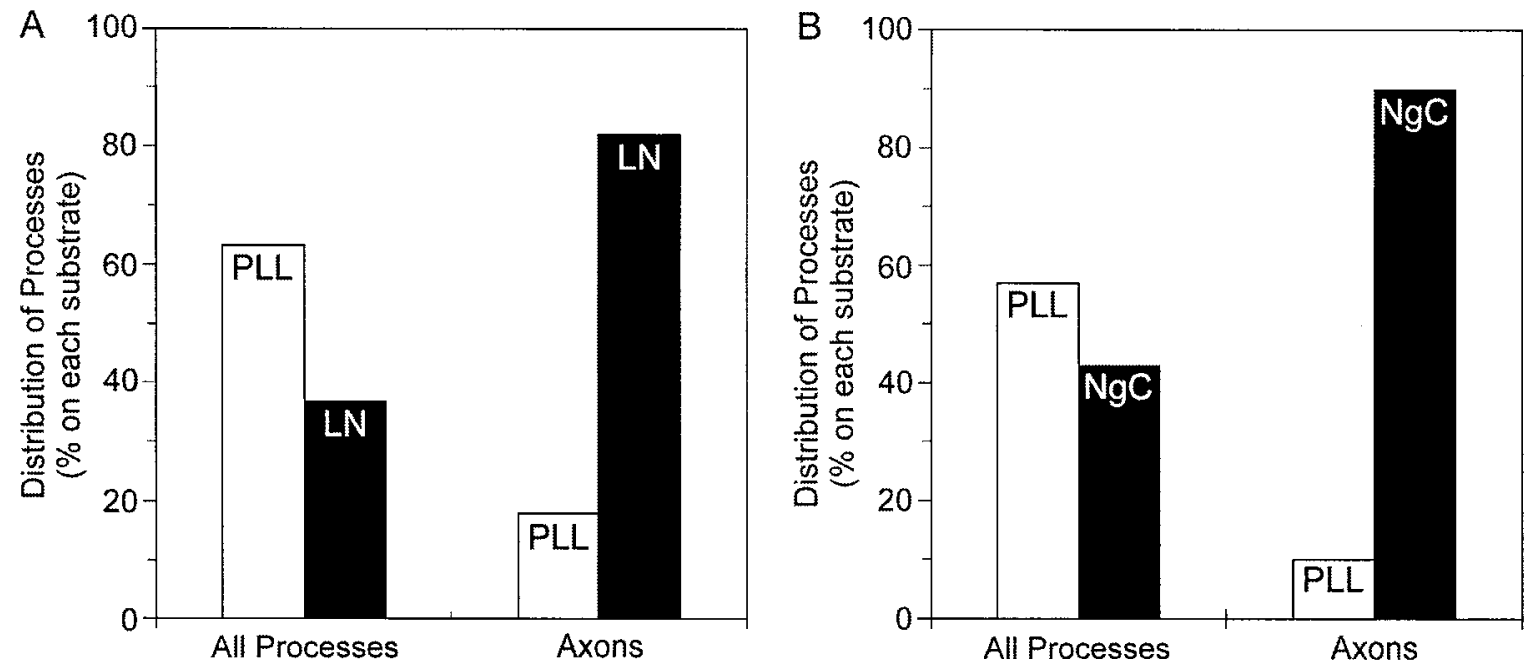

Figure 2. Quantification of the effects of $\mathrm{LN}$ and $\mathrm{NgCAM}$ on axon formation. The percentage of all processes and of axons that formed on each substrate was determined after $24 \mathrm{hr}$ in culture. $A$, Distribution of processes on PLL/LN stripes. $B$, Distribution of processes on PLL/NgCAM stripes. If axons formed equally well on both substrates, the percentage of all processes and the percentage of axons on each substrate would be equal. Instead, most of the axons formed from a process in which the growth cone contacted LN $\left(\chi^{2}=210 ; p<0.001 ; 264\right.$ cells counted) or NgCAM $(\mathrm{NgC})\left(\chi^{2}=64\right.$; $p<0.001 ; 156$ cells counted). Because the cells were examined only after axons had formed, we estimated the positions of growth cones at the time when the axon was specified (see Materials and Methods). Shown are combined data from two to three experiments.

placed in Minimal Essential Medium (MEM) containing $10 \%$ horse serum for plating. In some cases, instead of applying $\mathrm{LN}$ to the entire coverslip, we injected LN (100 $\mu \mathrm{g} / \mathrm{ml}$ in PBS) into the channels and incubated the coverslips for $2 \mathrm{hr}$ at $37^{\circ} \mathrm{C}$ before injecting fluoresceinconjugated BSA. Comparable results were obtained with both methods.

$P_{L L} / \mathrm{NgCAM}$ stripes. Acid-washed glass coverslips were incubated overnight in $1 \%$ protamine sulfate in water at $37^{\circ} \mathrm{C}$. The coverslips were rinsed several times with water, air-dried, and inverted onto the silicon matrix. PLL (1 $\mathrm{mg} / \mathrm{ml}$ in borate buffer) was injected into the matrix channels and incubated for $2 \mathrm{hr}$ at $37^{\circ} \mathrm{C}$. Then fluorescein-conjugated BSA ( $2 \%$ in PBS) was injected into the channels and incubated for $1.5 \mathrm{hr}$ at $37^{\circ} \mathrm{C}$ to block possible $\mathrm{NgCAM}$ binding sites. This step was repeated once. Next the channels were rinsed three to four times by injecting PBS, after which the coverslips were removed and rinsed two times in water. $\mathrm{NgCAM}(50 \mu \mathrm{g} / \mathrm{ml}$ in PBS) was applied to the entire coverslip and incubated for $2 \mathrm{hr}$ at $37^{\circ} \mathrm{C}$. Coverslips were rinsed three times in water and placed in MEM with $10 \%$ horse serum for plating.

LN/NgCAM stripes. Acid-washed glass coverslips were incubated overnight in $1 \%$ protamine sulfate in water at $37^{\circ} \mathrm{C}$. Coverslips were rinsed several times with water, air-dried, and inverted onto the silicon matrix. LN $(100 \mu \mathrm{g} / \mathrm{ml}$ in PBS) was injected into the matrix channels and incubated for $2 \mathrm{hr}$ at $37^{\circ} \mathrm{C}$. Then fluorescein-conjugated BSA $(2 \%$ in PBS) was injected into the channels, and the coverslips were treated in the same manner as described above for PLL/NgCAM stripes. In our experience $\mathrm{LN} / \mathrm{NgCAM}$ stripes were more difficult to produce reliably than either PLL/LN or PLL/NgCAM stripes. Borders between LN and $\mathrm{NgCAM}$ were not always crisp, and blocking was sometimes incomplete so that $\mathrm{NgCAM}$ bound in the same regions as $\mathrm{LN}$. In some regions there appeared to be a buildup of material at the borders between lanes that prevented neurites from crossing. These problems should not affect our results, however, because for all substrate combinations we included data only from regions of the coverslip where the lanes were crisp (based on immunostaining at the end of the experiment) and only counted cells that had at least one neurite that crossed a border.

\section{Cell culture}

Hippocampal cultures were prepared as described previously (Goslin et al., 1998). Hippocampi from $18 \mathrm{~d}$ fetal rats were dissected and treated with trypsin $\left(0.25 \%\right.$ for $15 \mathrm{~min}$ at $\left.37^{\circ} \mathrm{C}\right)$ and dissociated by trituration with a Pasteur pipette. Cells were plated at a density of $\sim 2000 \mathrm{cells} / \mathrm{cm}^{2}$ on substrate-coated glass coverslips in MEM containing $10 \%$ horse serum. After $2 \mathrm{hr}$ were allowed for cell attachment, the coverslips were transferred to dishes containing a confluent monolayer of glia in serumfree MEM with N2 supplements (Bottenstein and Sato, 1979; Bottenstein, 1985$), 0.1 \%$ ovalbumin, and $0.1 \mathrm{~mm}$ pyruvate.

\section{Analysis of fixed cells}

Immunofluorescence microscopy. Approximately $24 \mathrm{hr}$ after plating the cells were fixed for 20-30 min in 4\% paraformaldehyde in PBS containing $4 \%$ sucrose, permeabilized in $0.25 \%$ Triton $\mathrm{X}-100$ for $5 \mathrm{~min}$, and rinsed several times in PBS. Coverslips were blocked with $10 \%$ BSA in PBS for $1 \mathrm{hr}$ at $37^{\circ} \mathrm{C}$ and then incubated with either anti-tubulin (1:200) or tau-1 (1:100) and either anti-LN (1:200) or anti-NgCAM (1:500) antibodies (in $3 \% \mathrm{BSA} / \mathrm{PBS}$ ) for $1 \mathrm{hr}$ at $37^{\circ} \mathrm{C}$ or overnight at $4^{\circ} \mathrm{C}$. Coverslips were rinsed three times (15 min each) with PBS and incubated with Cascade Blue- and rhodamine-conjugated secondary antibodies (1:600 each) for $1 \mathrm{hr}$ at $37^{\circ} \mathrm{C}$. Coverslips again were rinsed three times (for 15 min each) with PBS, rinsed briefly in water, and then mounted on glass slides in a polyvinyl alcohol-based mounting medium containing $2 \%$ diazobicyclo-octane.

Fluorescence images were acquired with a Zeiss Axiophot microscope, a Photometrics AT-200 cooled charge-coupled device (CCD) camera, and Metamorph image analysis software (Universal Imaging, West Chester, PA). Cell and substrate images were superimposed with Metamorph so that the position of cells could be visualized in relation to stripes.

Data analysis. Only cells that had at least one growth cone contacting each substrate were analyzed. Because fixed cells were examined only after axons had formed, it was necessary to use these images to estimate the position of growth cones at the time of axon formation. Because the length of minor processes that do not become the axon changes little over the first $24 \mathrm{hr}$ in culture, we used the position of their growth cones at 24 $\mathrm{hr}$ as an estimate of their position at the time of axon formation. The position of the axon growth cone at the time of axon initiation was taken to be at a position along the axon $35 \mu \mathrm{m}$ from its base. This estimate was based on previous time-lapse studies of neurons growing on uniform PLL substrates, which show that the position of neurites does not change after the axon forms and that the transition from a minor process to an axon appears to occur when the minor process is $\sim 35 \mu \mathrm{m}$ long (J. Cooper and $\mathrm{G}$. Banker, unpublished observations). Although this approach is not exact, the errors should be equal for each substrate and therefore should cancel each other.

Time-lapse studies of neurons growing on striped substrates confirmed the validity of these estimates. Of 77 cells recorded on striped substrates before and after axon initiation, only three shifted position. In all three cases the soma migrated from the middle of the PLL stripe to overlap the $\mathrm{LN}$ border after the axon had formed on $\mathrm{LN}$, a change that would not have altered our conclusions if the cells had been examined only after 24 hr. Of 125 minor processes that were recorded continuously for many hours, only 13 would have been miscounted if they had been examined 

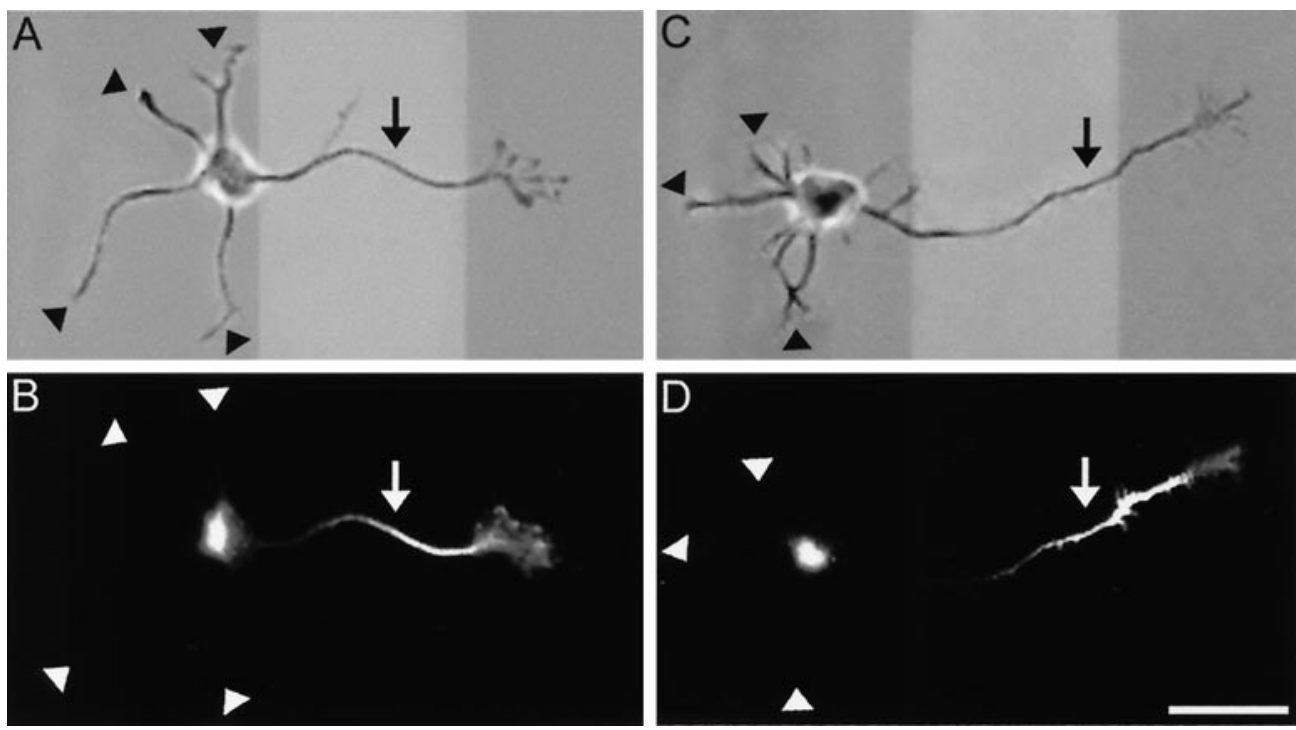

Figure 3. Neurons that develop on striped substrates appropriately polarize marker proteins. Cells were fixed $\sim 24$ hr after plating and were double-immunolabeled for tau-1 and LN. $A, C$, Combined phase/fluorescence images showing cells positioned on stripes (LN is light). $B, D$, Tau-1 immunofluorescence. Tau-1 labeling is concentrated in the nascent axon (arrows) and absent from the minor processes (arrowheads) even in axons as short as $55 \mu \mathrm{m}(A, B)$.

only at the end of the recording. Because approximately the same number of processes crossed onto LN or NgCAM as crossed onto PLL, the distribution measured after $24 \mathrm{hr}$ would not have been significantly different from the distribution at the time of axon formation.

The $\chi^{2}$ test was used to compare the distribution of minor process growth cones (including the process that became the axon) on each substrate with the distribution of axons on each substrate. Results are based on three experiments for cells grown on PLL/LN stripes, two experiments on PLL/NgCAM stripes, and six experiments on $\mathrm{LN} / \mathrm{Ng}$ CAM stripes.

\section{Time-lapse studies}

Video microscopy. Approximately $5 \mathrm{hr}$ after plating the neuronal coverslips were sealed in a recording chamber containing $400 \mu \mathrm{l}$ of glialconditioned medium and placed on a Zeiss IM-35 inverted microscope equipped with a heated stage driven by a Centroid motor controller. Cells were visualized with phase-contrast optics, and stripes were visualized by fluorescence (using fluorescent BSA to mark the lanes as described above). Of the cells, 8-12 were selected for recording, and phase-contrast images of each cell were collected every 5 min for 12-18 hr, using a Neuvicon video camera and Image-1 software (Universal Imaging). Images were stored on an optical memory disk recorder (OMDR). At the beginning and end of the recording session, a combined phase-contrast and fluorescence image of each cell also was recorded with a silicon-intensified target (SIT) camera to view positions of cells relative to the stripes. At the end of the recording the coverslips were fixed and stained with antibodies against tubulin and either LN or $\mathrm{NgCAM}$, as described above, to assess the quality of the stripes. Cells were not analyzed if substrate borders were not well defined.

Data analysis. All isolated cells that formed a single axon and had at least one process that had crossed from PLL onto LN or NgCAM during the recording session were analyzed. For each 5 min interval starting $\sim 3$ $\mathrm{hr}$ before and continuing $\sim 3 \mathrm{hr}$ after axon formation, the length of every process was measured with Image- 1 software. The length was traced from the base of the process to the center of the growth cone. To determine the position of each growth cone relative to the stripes, we compared the $x-y$ coordinates of the center of the growth cone with the $x-y$ coordinates of the stripes on fluorescence images. To correct for shifts in stage position between frames, we also tracked the position of a stationary object on the substrate. The length of each process and the position of its growth cone were plotted over time and compared with the location of the stripes.

\section{RESULTS \\ Local contact with LN or NgCAM can define neuronal polarity}

To determine whether local contact with substrates that accelerate axon growth can direct axon formation, we grew dissociated hippocampal neurons on coverslips patterned with alternating stripes of LN and PLL. When neurons developed for $24 \mathrm{hr}$ on these substrates, the axons almost always originated from processes that contacted LN (Fig. $1 A-C$ ). In cells that had their somata on PLL (Fig. 1A,C), the axon usually developed from a neurite that crossed onto $\mathrm{LN}$ within $30-40 \mu \mathrm{m}$ of its base. In some cases the axons crossed back onto PLL after traversing the LN stripe, but in others the axonal growth was restricted mainly to $\mathrm{LN}$. In cells with their somata on LN (Fig. 1B), most axons grew on LN for their entire length.

Interpretation of these results is based on the assumption that neurons fell randomly when plated on the patterned substrates and that minor processes contacted each substrate with equal probability. We found that $56 \%$ of neuronal somata attached to PLL, and $44 \%$ were on LN; this is the distribution expected, because the PLL stripes were $45 \mu \mathrm{m}$ wide whereas the LN stripes were $35 \mu \mathrm{m}$ wide. We found that $63 \%$ of processes contacted PLL. To quantify the ability of LN to induce axon formation, we compared the percentage of processes contacting each substrate with the percentage of axons that formed on each substrate.

We found that most axons formed on $\mathrm{LN}$ despite the fact that slightly more minor processes had their growth cones on PLL at the time of axon specification (Fig. $2 A$ ). Specifically, whereas only $37 \%$ of minor process growth cones were determined to be on $\mathrm{LN}$ at the time of axon formation, $82 \%$ of axons formed from these minor processes $\left(\chi^{2}=209.6 ; p<0.001\right)$. This effect was strongest for neurons with somata on PLL; for these cells $29.7 \%$ of minor process growth cones were calculated to be on $\mathrm{LN}$ at the time of axon formation, and $86.1 \%$ of the axons formed from these processes $\left(\chi^{2}=237 ; p<0.001\right)$. The effect was smaller but still statistically significant for cells that had their somata on LN. In 

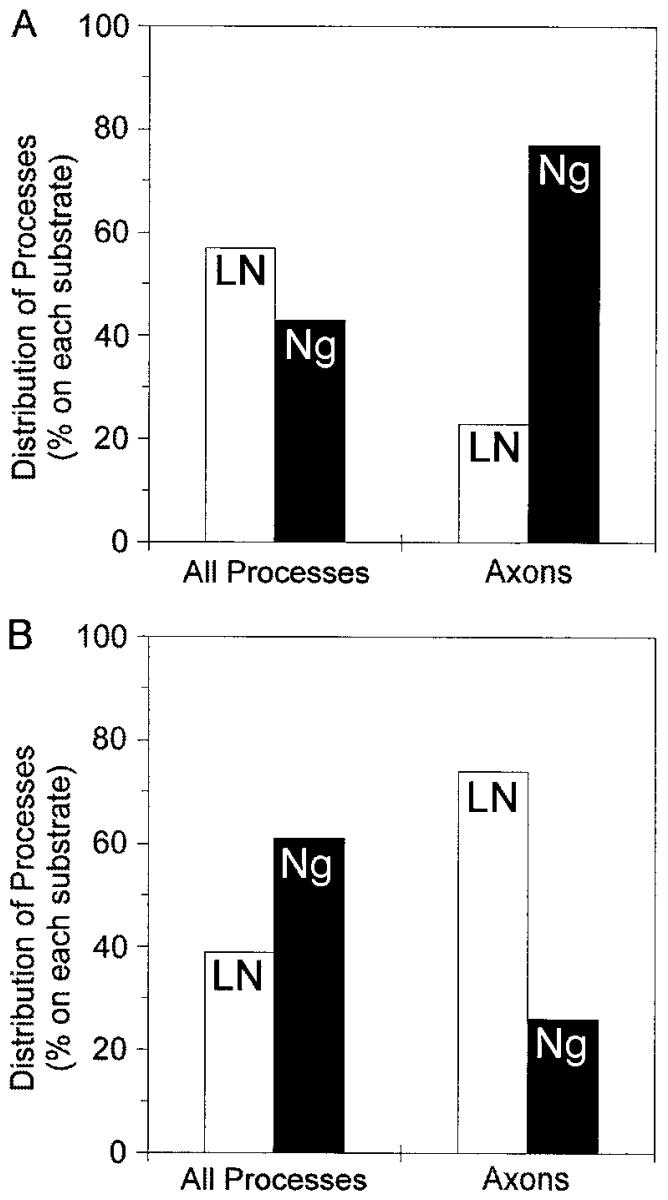

Figure 4. Axon specification on stripes of LN/NgCAM depends on soma position. The percentage of all processes and of axons that formed on each substrate was determined after $24 \mathrm{hr}$ in culture. $A$, Distribution of processes for cells with somata on LN. Most axons formed from a process for which the growth cone contacted $\operatorname{NgCAM}(N g)\left(\chi^{2}=19.28 ; p<0.001\right.$; 60 cells counted). $B$, Distribution of cells with somata on NgCAM. Most of the axons formed from a process whose growth cone contacted LN $\left(\chi^{2}=58.66 ; p<0.001 ; 159\right.$ cells counted $)$. Because the cells were examined only after axons had formed, we estimated the positions of growth cones at the time when the axon was specified (see Materials and Methods). Shown are combined data from six experiments.

these cells $54.0 \%$ of minor process growth cones were determined to be on $\mathrm{LN}$, and $69.6 \%$ of the axons emerged from these processes $\left(\chi^{2}=9.96 ; p<0.01\right)$. These results suggest that minor processes that contact $\mathrm{LN}$ are much more likely to develop into the axon of the cell than those processes that do not.

Local contact with $\mathrm{NgCAM}$ also stimulates axon formation. In neurons grown on alternating stripes of PLL and NgCAM, the axons were restricted almost entirely to NgCAM (see Fig. 1D$F$ ). Statistical analyses confirmed that the majority of axons formed from processes that contacted NgCAM (Fig. 2B). Although $40 \%$ of minor processes growth cones were calculated to be on $\mathrm{NgCAM}$ at the time of axon formation, $91 \%$ of axons formed from these processes $\left(\chi^{2}=74.34 ; p<0.001\right)$. The magnitude of this effect was equally strong independent of whether the soma had attached to PLL or NgCAM; in both cases $91 \%$ of axons formed on NgCAM. Thus contact with either NgCAM or LN greatly increases the probability that a minor process will develop into the axon of the cell.
In some experiments, tau- 1 immunostaining was used to confirm that axons identified by morphological criteria also exhibited the expected molecular characteristics (Fig. 3). Tau-1 labeling was present in axons, primarily in their distal portions, and was absent from minor processes. This was true even in short axons that had grown only the width of the LN stripe (Fig. $3 A, B$ ).

\section{LN/NgCAM stripes}

The experiments described thus far indicate that local contact with an axon-promoting substrate can influence which of a cell's neurites goes on to become the axon. We next asked whether LN or $\mathrm{NgCAM}$ would prove dominant in specifying the axon if cells were grown on alternating stripes of these axon-promoting substrates; alternatively, would axons show no preference but rather form with equal probability on both substrates? The results of this experiment, shown in Figure 4, were inconsistent with either prediction. In the case of cells that had their somata on $\mathrm{LN}$, axons formed preferentially on NgCAM, whereas cells with their somata on NgCAM formed axons predominantly on LN. This suggests that both substrates were approximately equal in their growth-promoting abilities and that growth from one axonpromoting substrate to another was a more potent stimulus for axon specification than continuous growth on a single substrate.

\section{Contact with the preferred substrate rapidly induces axonal growth}

To investigate the changes that occur when a growth cone contacts LN, we examined neurons growing on striped substrates, using time-lapse video microscopy. Images were recorded at 5 min intervals for $10-16 \mathrm{hr}$, beginning $6-8 \mathrm{hr}$ after plating. Because filopodial contact with LN could not be measured reliably with phase optics, we considered contact to occur when the central region of the growth cone crossed the border between PLL and $\mathrm{LN}$.

When a single minor process of a neuron growing on PLL crossed onto LN, that process almost always became the axon of the cell ( 9 of 11 cells). A representative cell is illustrated in Figure 5. Initially, all of the processes of the cell were on PLL (Fig. 5A) and had a similar growth pattern, exhibiting alternating periods of growth and partial retraction (Fig. $5 E$ ). When one process grew enough to cross onto the LN stripe, its growth pattern changed (Fig. $5 B, C$ ): the process grew rapidly and without significant retraction for an extended period of time (Fig. $5 E$ ). Such extended growth is characteristic only of axons in these cultures (Dotti et al., 1988; J. Cooper and G. Banker, unpublished observations).

An immediate increase in growth rate typically occurred when the growth cone of a neurite crossed onto LN. On average, the growth rate increased from $12.9 \mu \mathrm{m} / \mathrm{hr}$ in the $15 \mathrm{~min}$ before the cross to $48.3 \mu \mathrm{m} / \mathrm{hr}$ in the $15 \mathrm{~min}$ after the cross $(n=9 ; p<$ $0.005)$. In most cases the increase in growth rate was sustained for at least $1 \mathrm{hr}$; regression analysis showed that the rate increased from $11.4 \mu \mathrm{m} / \mathrm{hr}$ for the $1 \mathrm{hr}$ before encountering $\mathrm{LN}$ to 35.1 $\mu \mathrm{m} / \mathrm{hr}$ for the $1 \mathrm{hr}$ after crossing onto LN ( $n=9 ; p<0.05)$. These results suggest that, when a growth cone crosses onto LN, it immediately begins the transition into an axon.

Although only one process contacted LN, this interaction induced a change in the behavior of the entire cell (Fig. 6). The other processes of the cell, which had been exhibiting a slow net growth, now exhibited an overall retraction. The moment the first process contacted $\mathrm{LN}$ can be seen as an inflection both in the rate of the growing axon and in the total growth of the remaining 


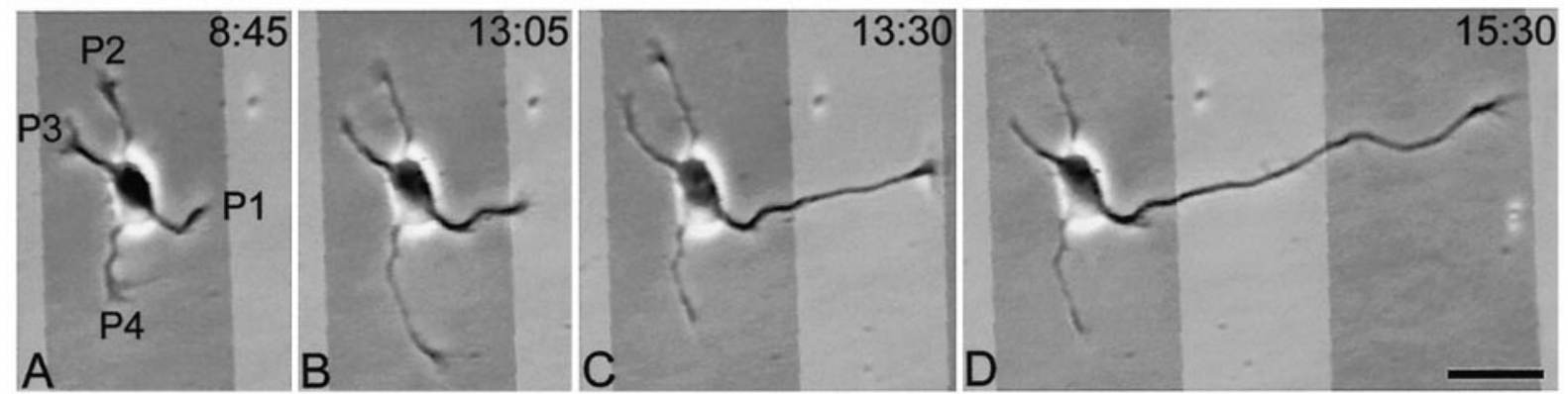

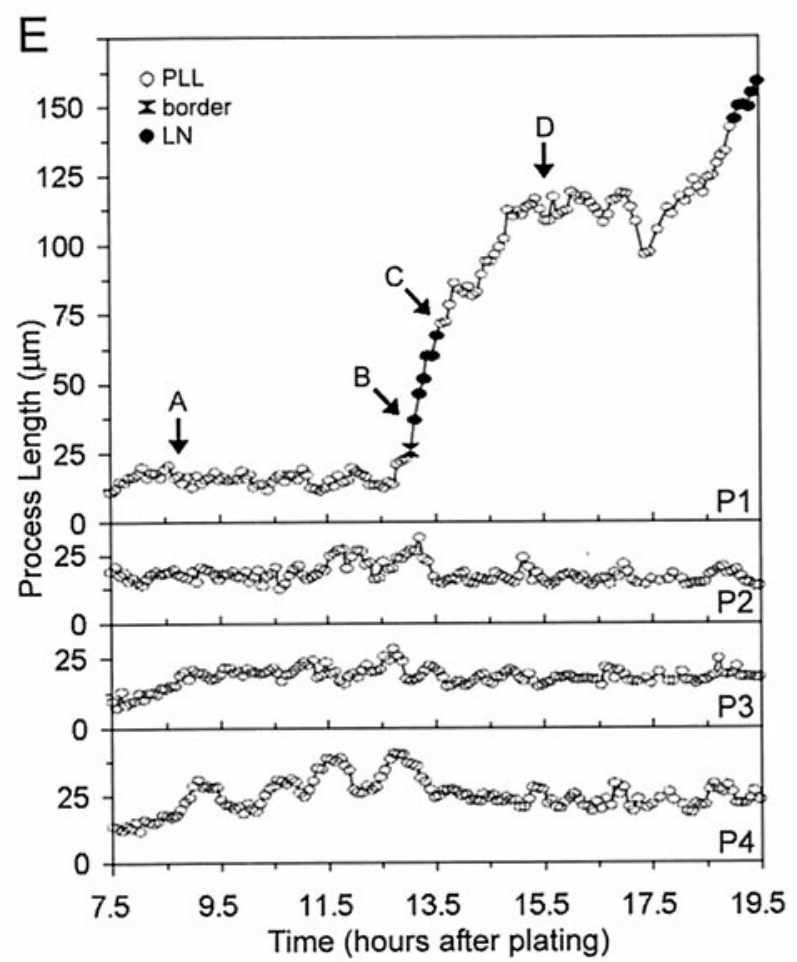

processes. In cells growing on uniform substrates of PLL, LN, or $\mathrm{NgCAM}$, such a retraction of minor processes is among the first indications that the polarity of a cell has been defined (T. Esch, J. Cooper, and G. Banker, unpublished observations). Thus, when a growth cone contacts $\mathrm{LN}$, this rapidly initiates a shift toward polarity that involves the cell as a whole.

After rapidly growing processes contacted the far side of a $\mathrm{LN}$ stripe and encountered PLL, they exhibited a range of behaviors. Typically, growth slowed or stopped temporarily. In the cell illustrated in Figure 5 the pause lasted $\sim 30 \mathrm{~min}$ (see Fig. $5 E$, at $\sim 13.5 \mathrm{hr}$ ); in others it lasted as long as several hours. When growth resumed, sometimes the process continued growing across PLL (see Fig. 5D); sometimes the process turned and continued growing on $\mathrm{LN}$; and sometimes the original process remained stalled, but a branch formed proximally and grew along the LN stripe.

Although contact with LN induced rapid growth in all cases, in two of the 11 cells observed the first process that crossed onto LN did not become the axon. Instead, when the process approached the far border with PLL, it retracted to within a few micrometers of its initial length. Eventually, a process that was growing on PLL became the axon. These results suggest that, although LN initiates the transition of a minor process into the axon, the process is not always maintained as the axon if its growth is interrupted.
Figure 5. Time-lapse images showing axon formation after contact with LN. $A-D$, Phase micrographs photographically lightened in regions corresponding to the LN stripes. $E$, Length of processes over time. All minor process growth cones were on PLL at the beginning of the recording $(A, E)$. Immediately after the growth cone of one process $(P 1)$ crossed onto LN $(B)$, the process grew rapidly across the stripe $(C, E)$. On reaching the far side of $\mathrm{LN}$, the growth of $P 1$ slowed $(E)$, but ultimately it grew across the PLL stripe and acquired a length characteristic of axons $(D)$. In $E$, the letters correspond to the frames depicted in $A-D$; open circles represent growth cone contact with PLL, black circles represent growth cone contact with LN, and black hourglasses represent growth cone contact with a border between two substrates. Scale bar, $25 \mu \mathrm{m}$.

When multiple growing processes contacted LN at approximately the same time, a competition between them ensued that continued for an extended period. A cell representative of the six cases we observed is illustrated in Figure 7. Two processes contacted LN within a $20 \mathrm{~min}$ period (Fig. $7 B$ ). One of these processes (Fig. 7, P1) exhibited several periods of rapid growth followed by retractions, but the growth cones of both processes remained near the PLL/LN border for $\sim 4 \mathrm{hr}$. Eventually, one process grew to become the axon of the cell (Fig. $7 E$ ). In the six cells that were examined, contact with $\mathrm{LN}$ initiated an average increase in rate of growth from $6.2 \mu \mathrm{m} / \mathrm{hr}$ in the $15 \mathrm{~min}$ before the cross to $23.2 \mu \mathrm{m} / \mathrm{hr}$ in the $15 \mathrm{~min}$ after the cross $(p<0.01)$, but in most cases this growth was not sustained. In all cases, however, one of the processes contacting LN eventually entered a period of sustained growth and became the axon of the cell. Thus when two or more neurites contact LN simultaneously, one of them usually becomes the axon, but the transition is delayed as compared with cases in which a single process crosses onto LN.

Contact with $\mathrm{NgCAM}$ directed axon formation in a manner similar to that with $\mathrm{LN}$ (based on observations of eight cells). In most cases, when a process crossed from PLL to NgCAM, there was an immediate increase in growth rate (data not shown). On average, the rate of growth increased from $8.9 \pm 1.9 \mu \mathrm{m} / \mathrm{hr}$ in the $15 \mathrm{~min}$ before to $28.8 \pm 4.1 \mu \mathrm{m} / \mathrm{hr}$ in the $15 \mathrm{~min}$ after a process 


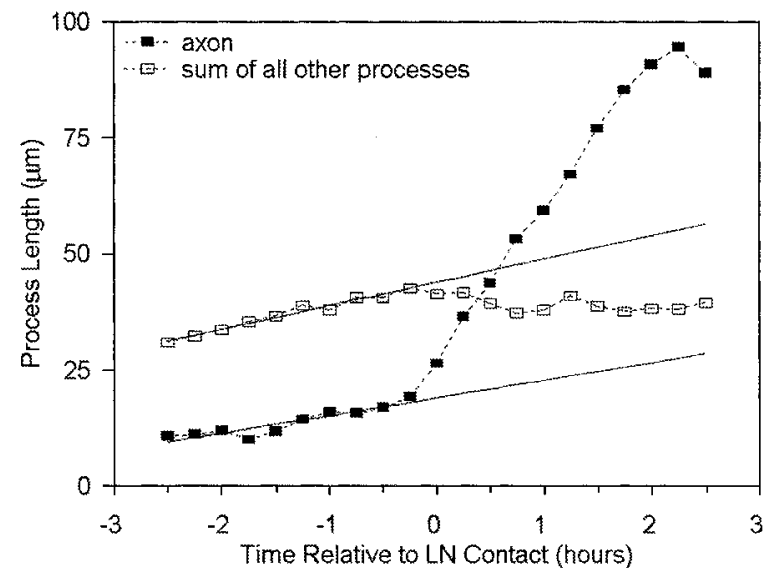

Figure 6. When a process contacts $\mathrm{LN}$, its growth rapidly increases, whereas the growth of the remaining processes decreases. This plot compares the length of the contacting process (the axon, filled squares) with the total length of the remaining minor processes (open squares). Before contact with $\mathrm{LN}$ all processes exhibit the same pattern of growth. Once a single growth cone crosses onto a LN stripe, the overall behavior of the neuron changes and growth is directed primarily to the axon. Measurements from different cells $(n=9)$ were aligned to the time point when the process first contacted LN (time 0 ). Regression lines (solid lines) show the predicted trajectory if growth had continued at the same rate as before contact with LN.

crossed from PLL onto $\operatorname{NgCAM}(n=12 ; p<0.001)$. When multiple processes contacted $\mathrm{NgCAM}$, the accelerated growth was not always sustained, but in seven of eight cells the axon ultimately formed from a process growing on $\mathrm{NgCAM}$.

\section{DISCUSSION}

The purpose of this study was to test the hypotheses that any of the neurites that initially develop from cultured hippocampal neurons are capable of becoming axons and that local extracellular signals can direct axon specification. To address these questions, we cultured neurons on coverslips patterned with alternating stripes of different substrate proteins. When an unspecified neurite crossed from PLL onto either LN or NgCAM, it frequently entered an extended period of growth and became the axon of the cell. Time-lapse analysis revealed that changes in the pattern of cell growth began almost immediately after one of its growth cones contacted the preferred substrate. These results suggest that novel contact with either of two substrate molecules from widely disparate protein families can cause a neurite for which the identity is not yet specified to become an axon and thereby determine the polarity of the cell.

Specification of the axon is a fundamental step in neuronal development, yet remarkably little is known about the factors that govern this event in vivo. Paralleling the behavior of cultured neurons (Dotti et al., 1988; Goslin and Banker, 1990), developing retinal ganglion cells studied in whole-mount preparations initially extend two or three processes in random directions (Brittis and Silver, 1995). The neurite directed appropriately persists as the axon. Brittis and Silver (1995) hypothesized that stabilization of the process that became the axon of the ganglion cell was a result of its contact with previously formed axons that expressed specific cell adhesion molecules, including L1. In the present study, using a cell culture model, we have demonstrated directly that contact with NgCAM, an L1-like molecule, as well as other substrate-attached molecules can specify the axon. Moreover, this approach has allowed us to visualize the rapid sequence of events leading to the establishment of polarity, a process that would be difficult to observe in intact tissue.

\section{Contact with a preferred substrate induces a rapid increase in the rate of neurite growth}

When the growth cone of a neurite first contacts LN or NgCAM, that process immediately begins to grow. This implies that contact with a preferred substrate must initiate a series of events that ultimately lead to selective elongation and stabilization of microtubules in the neurite (Lin et al., 1994) as well as expansion of its plasma membrane (Futerman and Banker, 1996; Jareb and Banker, 1997). Microtubule extension is thought to be regulated by actin dynamics (Suter and Forscher, 1998), which may play an important role in axon formation (Bradke and Dotti, 1999). Other studies have shown that contact with NgCAM or LN can cause a redistribution of actin that may allow forward extension of the microtubule network within the growth cone (Burden-Gulley and Lemmon, 1996). In addition, contact with LN causes a movement of organelles into the periphery of the growth cone (Rivas et al., 1992), possibly associated with the insertion of new plasma membrane. Although the molecular pathways that link receptor-substrate binding to neurite growth are not fully understood, they appear to involve calcium influx (Williams et al., 1992; Bixby et al., 1994; Kuhn et al., 1998) and activation of protein kinases and phosphatases (Bixby, 1989; Ignelzi et al., 1994; Klinz et al., 1995; Kuhn et al., 1995; Williams et al., 1995; Kunz et al., 1996). In addition to these signal-mediated events, the binding of cell surface receptors to substrate-attached ligands also may directly modify the interaction between these receptors and the submembranous actin cytoskeleton (Davis et al., 1993; Davis and Bennett, 1994; McKerracher et al., 1996), and also regulate their cell surface expression (Condic and Letourneau, 1997; Kamiguchi et al., 1998).

The signaling events that are initiated when a process first encounters a favorable substrate may be greater than those that occur during continuous growth on that substrate. When neurites growing on PLL cross onto LN and become axons, their initial rate of growth is more rapid than that of axons that form on uniform LN substrates (48 vs $27 \mu \mathrm{m} / \mathrm{hr}$; our unpublished observations). Moreover, on some substrate combinations the axons formed preferentially from those neurites that encountered a novel substrate. When cells were grown on stripes of $\mathrm{LN}$ and $\mathrm{NgCAM}$, cells that had their somata on LN preferentially formed axons on $\mathrm{NgCAM}$, and cells with their somata on $\mathrm{NgCAM}$ formed axons preferentially on LN. On stripes of PLL and LN the preference for axons to form on $\mathrm{LN}$ was greater when the soma was on PLL than when the soma was on LN. Perhaps the concentration of receptors for substrate molecules is downregulated after extended growth. For example, Condic and Letourneau (1997) have shown that the level of integrins in the plasma membrane is post-translationally regulated and inversely related to the concentration of $\mathrm{LN}$ on the substrate. Alternatively, the signal initiated when a receptor interacts with its substrate-bound ligand may diminish during continuous contact.

\section{Local signals initiated at a single growth cone lead to global changes in neurite growth}

When an unspecified neurite contacts a preferred substrate, this leads not only to its own elongation but also to a reduction in the growth rate of the other processes of the cell, often resulting in 


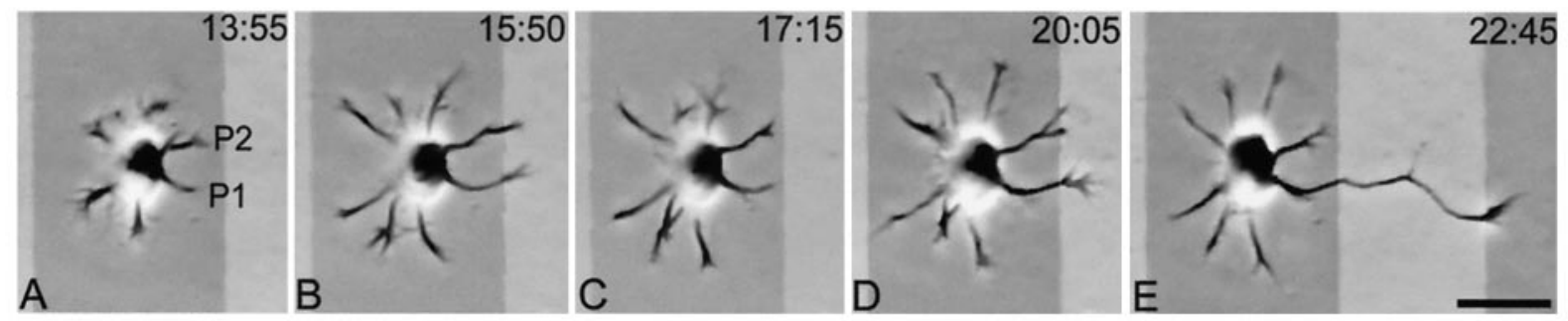

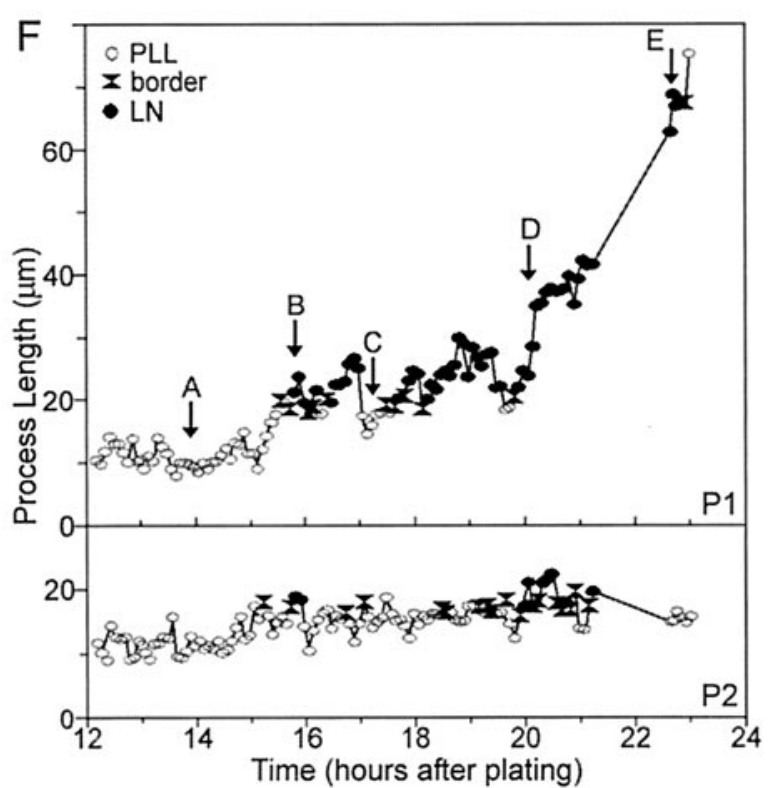

their net retraction. A similar phenomenon has been observed in cultures of Xenopus spinal neurons: application of cAMP to a single growth cone, which enhances its rate of elongation, also inhibits the growth of the other neurites of the cell (Zheng et al., 1994). Previous studies in hippocampal cultures have shown that the change in minor process growth, from net elongation to net retraction, is among the first indications that the development of polarity has begun (Dotti et al., 1988; J. Cooper and G. Banker, unpublished observations). The abruptness of the transition between these two patterns of growth is also striking (see Fig. 6); in just a matter of minutes the cell appears to pass from one state to another. It will be important to determine the temporal relationship between this transition in growth pattern and the appearance of the molecular differences, such as the dephosphorylation of the microtubule-associated protein tau and the concentration of GAP-43 and L1/NgCAM (Goslin et al., 1990; van den Pol and Kim, 1993; Mandell and Banker, 1996), that distinguish the developing axon.

We observed two circumstances in which contact with the preferred substrate was not sufficient to initiate the establishment of polarity. When two processes contacted LN at approximately the same time, both continued to grow and retract for some time, as if competing to become the axon. This suggests that, to specify neuronal polarity, the signal generated by contact with a preferred substrate must be restricted to a single neurite or must be significantly greater in one neurite than in the others. In some instances the process that first contacted LN did not become the axon if it stalled or retracted when it reached the far side of the LN stripe. This suggests that the signal generated when a growth cone contacts the preferred substrate must be sustained for some time to lead to axon specification. The requirement for a unique, sustained signal could serve as a control to prevent the formation of multiple axons and to correct errors if the axon began to form in the wrong direction.

\section{What is the instruction that specifies neuronal polarity?}

On the basis of an analysis of the consequences of transecting the axon at different distances from the soma, Goslin and Banker (1989) proposed a model for specification of the axon based on neurite length. According to this model the axon becomes specified when its length exceeds that of the cell's other neurites by a defined amount. One prediction of this model is that any signal that enhances neurite elongation should, if locally presented, cause an unspecified process to become the axon. The present results are consistent with this model, because contact with LN or L1/NgCAM (Lein et al., 1992; Williams et al., 1992; our unpublished observations) is known to increase the rate of neurite elongation. Alternatively, contact with $\mathrm{LN}$ or $\mathrm{NgCAM}$ may be a specific signal for axonal differentiation, the persistent growth that follows contact with these substrates being a downstream result. In neurons that have become polarized already, NgCAM and $\mathrm{LN}$ enhance axonal, but not dendritic, elongation even when 
uniformly presented (Lein et al., 1992; our unpublished observations); hence the second hypothesis is also plausible. It could be informative to compare the response of neurons to local contact with molecules that preferentially enhance dendritic rather than axonal growth (Lein et al., 1995; Withers, Higgins, Rueger, and Banker, quoted in Goslin et al., 1998), or that affect axonal and dendritic growth equally (Lafont et al., 1992). According to the first hypothesis the neurite that contacted the test substrate would become the axon, no matter what the substrate (so long as its rate of elongation increased). According to the second hypothesis whether the neurite that first contacted the test substrate became a dendrite or an axon would depend on the nature of the substrate.

The answer to this question may have important implications for the mechanisms that specify neuronal polarity in vivo. It is not known whether neurons in situ exhibit the overt competition between neurites that is observed in culture, but the underlying mechanisms that prevent neurons from forming more than a single axon may be similar in both situations. In situ, axons consistently arise from a given pole of the cell (relative to the overall organization of the tissue). In the case of hippocampal neurons, for example, axons arise from the basilar aspect of the soma. If differentiation of the axon requires a specific signal, there may be a separate, novel class of extracellular molecules for which the function is to govern the development of neuronal polarity. Alternatively, if specification of the axon is simply a function of differential growth, then any molecule that enhanced or inhibited neurite growth could, if differentially distributed, bias the rate of outgrowth from different poles of the cell and hence govern where the axon emerged. Many of the known molecules that guide growing axons, including the netrins and semaphorins, exhibit just these properties (for review, see Cook et al., 1998), and recent evidence suggests that inhibitory semaphorins present in the marginal zone of the cerebral cortex cause axons of cortical neurons to grow from the opposite pole of the cell (Polleux et al., 1998).

Our findings also may be of value for future studies of axonal specification in vitro. In previous investigations the inability to identify the nascent axon until polarity was already fully established has made it extremely difficult to study the events that lead to the specification of polarity. The ability to control which minor process develops into the axon via the use of localized substratebound cues offers an important new approach to investigate the mechanisms underlying this key event in neuronal development.

\section{REFERENCES}

Bixby JL (1989) Protein kinase C is involved in laminin stimulation of neurite outgrowth. Neuron 3:287-297.

Bixby JL, Grunwald GB, Bookman RJ (1994) $\mathrm{Ca}^{2+}$ influx and neurite growth in response to purified $\mathrm{N}$-cadherin and laminin. J Cell Biol 127:1461-1475.

Bottenstein JE (1985) Growth and differentiation of neural cells in defined media. In: Cell culture in the neurosciences (Bottenstein JE, Sato G, eds), pp 3-44. New York: Plenum.

Bottenstein JE, Sato GH (1979) Growth of a rat neuroblastoma cell line in serum-free supplemented medium. Proc Natl Acad Sci USA 76:514-517.

Bradke F, Dotti CG (1999) The role of local actin instability in axon formation. Science 283:1931-1934.

Brittis PA, Silver J (1995) Multiple factors govern intraretinal axon guidance: a time-lapse study. Mol Cell Neurosci 6:413-432.

Burden-Gulley SM, Lemmon V (1996) L1, N-cadherin, and laminin in- duce distinct distribution patterns of cytoskeletal elements in growth cones. Cell Motil Cytoskeleton 35:1-23.

Condic ML, Letourneau PC (1997) Ligand-induced changes in integrin expression regulate neuronal adhesion and neurite outgrowth. Nature 389:852-856.

Cook G, Tannahill D, Keynes R (1998) Axon guidance to and from choice points. Curr Opin Neurobiol 8:64-72.

Davis JQ, Bennett V (1994) Ankyrin binding activity shared by the neurofascin/L1/NrCAM family of nervous system cell adhesion molecules. J Biol Chem 269:27163-27166.

Davis JQ, McLaughlin T, Bennett V (1993) Ankyrin-binding proteins related to nervous system cell adhesion molecules: candidates to provide transmembrane and intercellular connections in adult brain. J Cell Biol 121:121-133.

Dotti CG, Banker GA (1987) Experimentally induced alteration in the polarity of developing neurons. Nature 330:254-256.

Dotti CG, Sullivan CA, Banker GA (1988) The establishment of polarity by hippocampal neurons in culture. J Neurosci 8:1454-1468.

Futerman AH, Banker GA (1996) The economics of neurite outgrowth - the addition of new membrane to growing axons. Trends Neurosci 19:144-149.

Goslin K, Banker G (1989) Experimental observations on the development of polarity by hippocampal neurons in culture. J Cell Biol 108:1507-1516.

Goslin K, Banker G (1990) Rapid changes in the distribution of GAP-43 correlate with the expression of neuronal polarity during normal development and under experimental conditions. J Cell Biol 110:1319-1331.

Goslin K, Schreyer DJ, Skene JH, Banker G (1990) Changes in the distribution of GAP-43 during the development of neuronal polarity. J Neurosci 10:588-602.

Goslin K, Asmussen H, Banker G (1998) Rat hippocampal neurons in low density culture. In: Culturing nerve cells (Banker G, Goslin K, eds), pp 339-370. Cambridge, MA: MIT.

Ignelzi Jr MA, Miller DR, Soriano P, Maness PF (1994) Impaired neurite outgrowth of $s r c^{-}$cerebellar neurons on the cell adhesion molecule L1. Neuron 12:873-884.

Jareb M, Banker G (1997) Inhibition of axonal growth by brefeldin A in hippocampal neurons in culture. J Neurosci 17:8955-8963.

Kamiguchi H, Long KE, Pendergast M, Schaefer AW, Rapoport I, Kirchhausen T, Lemmon V (1998) The neural cell adhesion molecule L1 interacts with the AP-2 adaptor and is endocytosed via the clathrinmediated pathway. J Neurosci 18:5311-5321.

Klinz SG, Schachner M, Maness PF (1995) L1 and N-CAM antibodies trigger protein phosphatase activity in growth cone-enriched membranes. J Neurochem 65:84-95.

Kuhn TB, Schmidt MF, Kater SB (1995) Laminin and fibronectin guideposts signal sustained but opposite effects to passing growth cones. Neuron 14:275-285.

Kuhn TB, Williams CV, Dou P, Kater SB (1998) Laminin directs growth cone navigation via two temporally and functionally distinct calcium signals. J Neurosci 18:184-194.

Kunz S, Ziegler U, Kunz B, Sonderegger P (1996) Intracellular signaling is changed after clustering of the neural cell adhesion molecules axonin-1 and NgCAM during neurite fasciculation. J Cell Biol 135:253-267.

Lafont F, Rouget M, Triller A, Prochiantz A, Rousselet A (1992) In vitro control of neuronal polarity by glycosaminoglycans. Development 114:17-29.

Lein PJ, Banker GA, Higgins D (1992) Laminin selectively enhances axonal growth and accelerates the development of polarity by hippocampal neurons in culture. Brain Res Dev Brain Res 69:191-197.

Lein P, Johnson M, Guo X, Rueger D, Higgins D (1995) Osteogenic protein-1 induces dendritic growth in rat sympathetic neurons. Neuron 15:597-605.

Lemmon V, McLoon SC (1986) The appearance of an L1-like molecule in the chick primary visual pathway. J Neurosci 6:2987-2994.

Lin CH, Thompson CA, Forscher P (1994) Cytoskeletal reorganization underlying growth cone motility. Curr Opin Neurobiol 4:640-647.

Lochter A, Schachner M (1993) Tenascin and extracellular matrix glycoproteins: from promotion to polarization of neurite growth in vitro. J Neurosci 13:3986-4000.

Mandell JW, Banker GA (1996) A spatial gradient of tau protein phosphorylation in nascent axons. J Neurosci 16:5727-5740.

McKerracher L, Chamoux M, Arregui CO (1996) Role of laminin and 
integrin interactions in growth cone guidance. Mol Neurobiol 12:95-116.

Polleux F, Giger RJ, Ginty DD, Kolodkin AL, Ghosh A (1998) Patterning of cortical efferent projections by semaphorin-neuropilin interactions. Science 282:1904-1906.

Rivas RJ, Burmeister DW, Goldberg DJ (1992) Rapid effects of laminin on the growth cone. Neuron 8:107-115.

Suter DM, Forscher P (1998) An emerging link between cytoskeletal dynamics and cell adhesion molecules in growth cone guidance. Curr Opin Neurobiol 8:106-116.

Tanaka E, Sabry J (1995) Making the connection: cytoskeletal rearrangements during growth cone guidance. Cell 83:171-176.

Tessier-Lavigne M, Goodman CS (1996) The molecular biology of axon guidance. Science 274:1123-1133.

van den Pol AN, Kim WT (1993) NILE/L1 and NCAM-polysialic acid expression on growing axons of isolated neurons. J Comp Neurol 332:237-257.

Vielmetter J, Stolze B, Bonhoeffer F, Stuermer CA (1990) In vitro assay to test differential substrate affinities of growing axons and migratory cells. Exp Brain Res 81:283-287.

Williams EJ, Doherty P, Turner G, Reid RA, Hemperly JJ, Walsh FS (1992) Calcium influx into neurons can solely account for cell contactdependent neurite outgrowth stimulated by transfected L1. J Cell Biol 119:883-892.

Williams EJ, Mittal B, Walsh FS, Doherty P (1995) $\mathrm{A} \mathrm{Ca}^{2+} /$ calmodulin kinase inhibitor, KN-62, inhibits neurite outgrowth stimulated by CAMs and FGF. Mol Cell Neurosci 6:69-79.

Zheng JQ, Zheng Z, Poo M (1994) Long-range signaling in growing neurons after local elevation of cyclic AMP-dependent activity. J Cell Biol 127:1693-1701. 